\title{
Papillary muscle relocation and mitral annuloplasty in ischemic mitral valve regurgitation: Midterm results
}

\author{
Khalil Fattouch, MD, PhD, ${ }^{\mathrm{a}}$ Sebastiano Castrovinci, MD, ${ }^{\mathrm{b}}$ Giacomo Murana, MD, ${ }^{\mathrm{b}}$ Pietro Dioguardi, MD, \\ Francesco Guccione, MD, ${ }^{\mathrm{a}}$ Giuseppe Nasso, MD, ${ }^{\mathrm{c}}$ and Giuseppe Speziale, $\mathrm{MD}^{\mathrm{c}}$
}

Objectives: The surgical approach for ischemic mitral regurgitation remains unclear. Many studies are in favor of adding the subvalvular procedure to mitral annuloplasty to reduce recurrent mitral regurgitation. This study reports the clinical and echocardiographic outcomes of papillary muscle relocation combined with mitral annuloplasty.

\begin{abstract}
Methods: From 2003, 115 patients with severe ischemic mitral regurgitation who underwent papillary muscle relocation plus nonrestrictive mitral annuloplasty and coronary artery bypass grafting were retrospective analyzed. Patients' mean age was $52 \pm 12.8$ years, New York Heart Association class III or IV was $71 \%$, and preoperative left ventricular ejection fraction was $43 \% \pm 6 \%$. The study end points were New York Heart Association functional class, reversal in left ventricle remodeling, reduction of mean tenting area and mean coaptation depth, freedom from cardiac-related deaths and events, and freedom from recurrent mitral regurgitation. Follow-up data were obtained in all patients and were $100 \%$ complete. Mean follow-up was $45 \pm 6$ months.

Results: Five-year freedom from cardiac-related death and events was $91.3 \% \pm 1.6 \%$ and $84 \% \pm 2.2 \%$, respectively. Recurrent mitral regurgitation more than moderate occurred in 3 patients $(2.7 \%)$. Reversal in left ventricular remodeling, measured by a change in the end-diastolic and systolic diameter, was observed in our patients $(P<.05)$. The postoperative mean tenting area and mean coaptation depth were $1.1 \pm 0.2 \mathrm{~cm}^{2}$ and $0.5 \pm 0.2 \mathrm{~cm}$, respectively; $95 \%$ of the patients were in New York Heart Association functional class I and II.

Conclusions: In patients with ischemic mitral regurgitation, papillary muscle relocation plus nonrestrictive mitral annuloplasty promotes a significant reversal in left ventricular remodeling, with a considerable decrease in tenting area and coaptation depth. Our approach is a durable method to reduce the recurrence of mitral insufficiency. (J Thorac Cardiovasc Surg 2014;148:1947-50)
\end{abstract}

In the era of mitral valve reconstruction, the surgical approach for ischemic mitral regurgitation (IMR) remains an open issue. ${ }^{1,2}$ Many surgeons prefer restrictive mitral valve annuloplasty (R-MA), whereas others prefer mitral valve replacement with subvalvular apparatus preservation to avoid postoperative mitral regurgitation (MR). ${ }^{3-8}$ The incidence of recurrent MR after isolated R-MA was 5\% to $20 \%$ in several reports. ${ }^{9,10}$ On the other hand, many authors have advocated postinfarction ventricular remodeling as the key issue in the development of IMR and suggest adding a subvalvular apparatus

\footnotetext{
From the Department of Cardiovascular Surgery, ${ }^{a}$ GVM Care and Research, Maria Eleonora Hospital, Palermo, Italy; Department of Cardiac Surgery, ${ }^{\mathrm{b}}$ University of Bologna, Bologna, Italy; and Department of Cardiovascular Surgery, ${ }^{\mathrm{c}} \mathrm{GVM}$ Care and Research, Anthea Hospital, Bari, Italy.

Disclosures: Authors have nothing to disclose with regard to commercial support.

Received for publication May 1, 2013; revisions received Jan 26, 2014; accepted for publication Feb 14, 2014; available ahead of print March 20, 2014.

Address for reprints: Khalil Fattouch, MD, PhD, Department of Cardiovascular Surgery, GVM Care and Research, Maria Eleonora Hospital, Viale Regione Siciliana 1571, 90100 Palermo, Italy (E-mail: khalilfattouch@hotmail.com). $0022-5223 / \$ 36.00$

Copyright (c) 2014 by The American Association for Thoracic Surgery http://dx.doi.org/10.1016/j.jtcvs.2014.02.047
}

procedure to annuloplasty to reduce the risk of recurrent mitral valve insufficiency. ${ }^{11-13}$ This study reports the midterm results of the clinical and echocardiographic outcomes of papillary muscle (PPM) relocation in conjunction with nonrestrictive mitral annuloplasty (NR-MA) in IMR.

\section{MATERIALS AND METHODS \\ Patients}

From March 2003, 115 patients (mean age, $52 \pm 12.8$ years; $56 \%$ were male) with severe IMR (effective regurgitant orifice area $\geq 20 \mathrm{~mm}^{2}$, regurgitant volume $\geq 30 \mathrm{~mL}$ ) who had PPM relocation in conjunction with NR-MA and coronary artery bypass grafting (CABG) were retrospectively analyzed. New York Heart Association (NYHA) class greater than II was present in 81 patients $(71 \%)$, and mean left ventricular ejection fraction (LVEF) was $43 \% \pm 6 \%$. According to Carpentier's functional classification, ${ }^{14}$ all patients with IMR presented restrictive systolic leaflets motion (Carpentier's type III b) and annular dilatation (Carpentier's type I). Mean coaptation depth and mean tenting area were $1.3 \pm 0.1 \mathrm{~cm}$ and $3.2 \pm 0.9 \mathrm{~cm}^{2}$, respectively. MR was defined as ischemic when caused by coronary artery disease in patients who had a previous myocardial infarction 2 weeks or more before hospital admission for CABG and exhibited normal valve apparatus anatomy. Exclusion criteria were recent myocardial infarction ( $<15$ days), PPM infarction causing its elongation or rupture, organic mitral valve lesions (rheumatic, infective, degenerative), 


$$
\begin{aligned}
& \text { Abbreviations and Acronyms } \\
& \begin{array}{ll}
\text { CABG } & =\text { coronary artery bypass grafting } \\
\text { CI } & =\text { confidence interval } \\
\text { HR } & =\text { hazard ratio } \\
\text { IMR } & =\text { ischemic mitral regurgitation } \\
\text { LV } & =\text { left ventricular } \\
\text { LVEF } & =\text { left ventricular ejection fraction } \\
\text { MR } & =\text { mitral regurgitation } \\
\text { NR-MA } & =\text { nonrestrictive mitral annuloplasty } \\
\text { NYHA } & =\text { New York Heart Association } \\
\text { PPM } & =\text { papillary muscle } \\
\text { R-MA } & =\text { restrictive mitral valve annuloplasty }
\end{array}
\end{aligned}
$$

previous cardiac surgery, and concomitant aortic valve surgery. Baseline patient characteristics are shown in Table 1.

\section{End Points}

The study end points were as follows: incidence of early mortality and outcomes, freedom from cardiac-related deaths and events, freedom from recurrent MR 2 or greater, NYHA functional class, reverse in left ventricular (LV) remodeling, evaluation of tenting area, and coaptation depth. A cardiac event was defined as the occurrence of at least 1 of the following: myocardial infarction, congestive heart failure, cardiac death, revascularization (CABG or percutaneous intervention), new onset of atrial fibrillation, redo operation on the mitral valve, worsening in NYHA functional class, recurrent MR grade of 2 or greater, and hospital readmission.

\section{Surgical Technique}

All patients underwent conventional multivessel CABG via a longitudinal median sternotomy under normothermic cardiopulmonary bypass with intermittent antegrade cold-blood cardioplegia. The bypass grafts used were the internal thoracic artery and the long saphenous vein in all patients. All distal anastomoses were performed during a single aortic crossclamping. The proximal graft anastomoses were performed during side-clamping (Table 1).

Mitral valve annuloplasty was performed using the Carpentier-Edwards Physio ring (Edwards Lifesciences, Irving, Calif) or the Saddle Rigid ring (St Jude Medical, Minneapolis, Minn). The ring size was determined according to the surface of the anterior leaflet. In regard to our nonrestrictive annuloplasty, we used the normal-sized ring, not the undersized. In patients who undergo PPM relocation, the use of a ring according to the anterior leaflet surface may be effective without having to risk an undersizing. Rings were inserted using deep horizontal $U$ sutures and Ticron 2-0 stitches (Syneture, Norwalk, Conn).

Relocation of the PPMs was performed using a polytetrafluoroethylene suture (CV-4 Gore-Tex; WL Gore \& Associates Inc, Flagstaff, Ariz) placed first at the head of each PPM and subsequently through the ipsilateral mitral annulus while the heart was arrested, according to the technique described by Kron and colleagues. ${ }^{12}$ We relocate both PPMs to minimize the mitral valve tenting. In most cases, 1 head of the anterior PPM was relocated. On the other hand, among the 3 heads of the posterior PPM, we relocated the anterior and posterior heads. It is important to relocate both heads of the posterior PPM because from the anterior, one head arises from the chordae for the anterior leaflet responsible for the seagull sign and respective tenting, and from the posterior, one head arises from the chordae to the posterior leaflet (P2 and P3 scallops). ${ }^{15}$

All patients underwent postoperative transesophageal assessment of the LV and valve function. Mitral valve repair was considered successful if there was no or trivial residual MR and a coaptation surface of approximately $0.8 \mathrm{~cm}$.

\section{Follow-up}

All patients were followed by our cardiologists at 6-month intervals. Preoperative and postoperative clinical status were determined according to the criteria of the NYHA functional class and the Canadian Cardiovascular Society for heart failure symptoms and angina, respectively. Clinical follow-up data were obtained in all patients and were $100 \%$ complete. Mean follow-up was $45 \pm 6$ months.

\section{Statistical Analysis}

The numeric values are expressed as mean \pm standard deviation. The frequency ratios are given as percentages. LV end-diastolic and end-systolic diameters, and LVEF percentage were analyzed using the paired $t$ test and Wilcoxon signed-rank test. Variables were put into a Cox regression model. Where appropriate, hazard ratios (HRs) are presented with $95 \%$ confidence intervals (CIs). Actuarial survival and other time-related events were analyzed with the Kaplan-Meier method. Log-rank test was used to compare statistical significance level. SPSS software (SPSS Inc, Chicago, Ill) was used.

\section{RESULTS}

\section{Early Outcomes}

Of the entire population, 4 patients $(3.4 \%)$ died in-hospital. Causes of in-hospital death were low cardiac output in 2 patients, sepsis in 1 patient, and multiorgan failure in 1 patient. Intra-aortic balloon pump implantation was required to treat postoperative cardiogenic shock in 2 patients $(1.7 \%)$. Renal failure requiring dialysis was present in 4 patients $(3.4 \%)$. All data are shown in Table 2.

\section{TABLE 1. Baseline and intraoperative data}

\begin{tabular}{lc}
\hline Baseline & \\
Mean age (y) & $52 \pm 12.8$ \\
Male gender & $65(56 \%)$ \\
Diabetes mellitus & $38(33 \%)$ \\
COPD & $12(10.4 \%)$ \\
Hypertension & $70(60 \%)$ \\
Renal failure* & $9(7.8 \%)$ \\
Unstable angina & $35(30.4 \%)$ \\
CHF & $44(38 \%)$ \\
Atrial fibrillation & $6(5.2 \%)$ \\
NYHA >II & $81(71 \%)$ \\
euroSCORE & $8.8 \pm 2.6$ \\
LVEF & $43 \pm 6$ \\
LVEDD & $58.8 \pm 12$ \\
LVESD & $48.1 \pm 9$ \\
Mean tenting area & $3.2 \pm 0.9$ \\
Mean coaptation depth & $1.3 \pm 0.1$ \\
Intraoperative & \\
CPB time (min) & $114 \pm 20$ \\
Crossclamp time (min) & $85 \pm 10$ \\
Grafts/patient & $2.8 \pm 0.5$ \\
\hline Values are mean \pm standard deviation or number (\%).CHF, Congestive heart failure; \\
COPD, chronic obstructive pulmonary disease; $C P B$, cardiopulmonary bypass; \\
euroSCORE, European System for Cardiac Operative Risk Evaluation; $L V E D D$, \\
left ventricular end-diastolic diameter; $L V E F$, left ventricular ejection fraction; \\
LVESD, left ventricular end-systolic diameter; $N Y H A$, New York Heart Association. \\
*Serum creatinine greater than 1.5 mg/dL. \\
\end{tabular}


TABLE 2. Early outcomes and follow-up data

\begin{tabular}{|c|c|}
\hline \multicolumn{2}{|l|}{ Early outcomes } \\
\hline Bleeding with resternotomy & $6(5.2 \%)$ \\
\hline Renal failure (dialysis) & $4(3.4 \%)$ \\
\hline $\mathrm{ETI}>72 \mathrm{~h}$ & $7(6 \%)$ \\
\hline LCOS & $2(1.7 \%)$ \\
\hline Sepsis & $1(0.8 \%)$ \\
\hline MOF & $1(0.8 \%)$ \\
\hline IABP & $2(1.7 \%)$ \\
\hline ICU stay $(\mathrm{d})$ & $2.1 \pm 1.8$ \\
\hline In-hospital mortality & $4(3.4 \%)$ \\
\hline \multicolumn{2}{|l|}{ Follow-up data } \\
\hline Late mortality & $5(4.5 \%)$ \\
\hline NYHA class $>$ II & $4(3.6 \%)$ \\
\hline Hospital readmission for $\mathrm{CHF}$ & $4(3.6 \%)$ \\
\hline Recurrent $\mathrm{MR} \geq \mathrm{II}$ & $3(2.7 \%)$ \\
\hline Mean tenting area $\left(\mathrm{cm}^{2}\right)$ & $1.1 \pm 0.2$ \\
\hline Mean coaptation depth $(\mathrm{cm})$ & $0.5 \pm 0.2$ \\
\hline $\operatorname{LVEDD}(\mathrm{mm})$ & $49 \pm 5$ \\
\hline $\operatorname{LVESD}(\mathrm{mm})$ & $39 \pm 4$ \\
\hline Mean LVEF\% $\%$ & $49 \pm 3$ \\
\hline \multicolumn{2}{|c|}{$\begin{array}{l}\text { Values are presented as mean } \pm \text { standard deviation or number }(\%) . C H F \text {, Congestive } \\
\text { heart failure; ETI, endotracheal intubation; IABP, intra-aortic balloon pump; } \\
I C U \text {, intensive care unit; } L C O S \text {, low cardiac output syndrome; } L V E D D \text {, left } \\
\text { ventricular end-diastolic diameter; } L V E F \text {, left ventricular ejection fraction; } \\
L V E S D \text {, left ventricular end-systolic diameter; } M O F \text {, multiorgan failure; } M R \text {, mitral } \\
\text { regurgitation; NYHA, New York Heart Association. }\end{array}$} \\
\hline
\end{tabular}

\section{Late Outcomes}

Kaplan-Meier estimate for cumulative survival at 5 years was $91 \% \pm 1.3 \%$ after PPM relocation plus NR-MA. Five-year freedom from cardiac-related death rate was $91.3 \% \pm 1.6 \%$ (Figure 1, A). Late cardiac deaths occurred in 5 patients $(4.5 \%)$. Causes of late death were congestive heart failure in 2 patients, arrhythmias in 2 patients, and sudden death in 1 patient. The following independent variables for late mortality in the entire population were found by Cox analysis: LVEF $30 \%$ or less $(P=.003$; HR, 8; 95\% CI, 2.2-37) and NYHA class III or greater $(P=.006 ;$ HR, $5.5 ; 95 \%$ CI, 1.5-44). Five-year freedom from cardiac-related events was $84 \% \pm 2.2 \%$ (Figure 1, B). Five-year freedom from recurrent MR grade of 2 or greater was $97.3 \% \pm 1.1 \%$ (Figure 1, C). At follow-up, NYHA functional class improved from $3.1 \pm 1.1$ to $1.3 \pm 0.3(P=.018)$.

\section{Echocardiographic Data}

Recurrent moderate or more than moderate MR occurred in 3 patients $(2.7 \%)$. Significant reversal in LV remodeling measured by a change in LV end-diastolic and end-systolic diameters was observed in our patients $(P<.05)$. The LVEF improved from $43 \pm 6$ to $49 \pm 3(P<.05)$. Postoperative mean tenting area was $1.1 \pm 0.2 \mathrm{~cm}^{2}$, and postoperative mean coaptation depth was $0.5 \pm 0.2 \mathrm{~cm}$, with significant reduction in respect to preoperative data $(P<.001)$ (Table 3).

\section{CONCLUSIONS}

Although the surgical treatment of severe IMR in patients presenting for CABG is recommended by the American College of Cardiology/American Heart Association and European Society of Cardiology/European Association for Cardiothoracic Surgery guidelines, ${ }^{1,2}$ the best surgical approach is still under debate. Several clinical studies provide only limited information about the dilemma to repair or replace the mitral valve in patients with severe IMR. ${ }^{5,7}$ This conflicting decision is mainly affected by the lack of prospective studies and often by the comparison of clinical outcomes for both procedures in dissimilar patient groups.

Currently, R-MA is still associated with poor outcomes in many series ${ }^{16,17}$ for many reasons. First, there is a wide heterogeneity in the literature in the type of prosthetic ring (eg, complete, band, rigid, flexible, pericardium) used to achieve mitral annuloplasty, which inexorably leads to dissimilar results. Second, R-MA was performed in all patients with IMR despite the degree of LV dilatation and
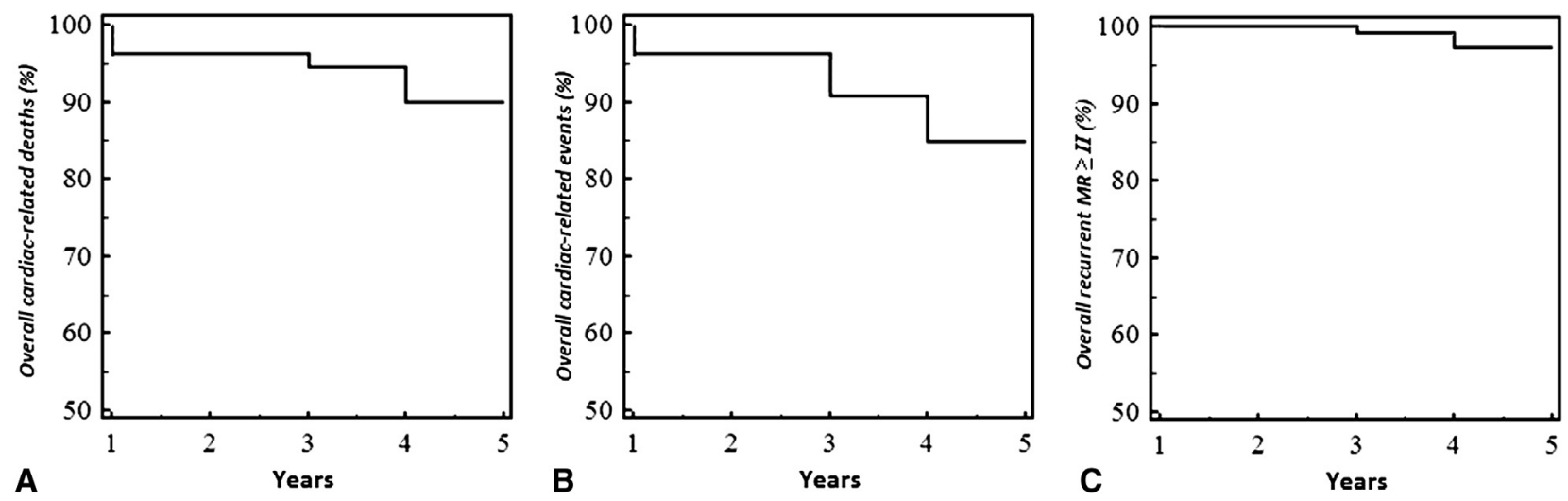

FIGURE 1. Kaplan-Meier log-rank test used to compare cardiac-related deaths (A), cardiac-related events (B), and recurrent MR grade of 2 or greater. $M R$, Mitral regurgitation. 
TABLE 3. Comparison of echocardiographic data from preoperative to follow-up

\begin{tabular}{lccc}
\hline \multicolumn{1}{c}{ Variable } & Preoperative & Follow-up & $\boldsymbol{P}$ value \\
\hline Mean tenting area $\left(\mathrm{cm}^{2}\right)$ & $3.2 \pm 0.9$ & $1.1 \pm 0.2$ & $<.001$ \\
Mean coaptation depth $(\mathrm{cm})$ & $1.3 \pm 0.1$ & $0.5 \pm 0.2$ & $<.001$ \\
LVEDD $(\mathrm{mm})$ & $58.8 \pm 12$ & $49 \pm 5$ & $<.05$ \\
LVESD $(\mathrm{mm})$ & $48.1 \pm 9$ & $39 \pm 4$ & $<.05$ \\
Mean LVEF\% & $43 \pm 6$ & $49 \pm 3$ & $<.05$ \\
\hline
\end{tabular}

Values are mean \pm standard deviation or number (\%). LVEDD, Left ventricular enddiastolic diameter; $L V E F$, left ventricular ejection fraction; $L V E S D$, left ventricular end-systolic diameter.

dysfunction and the severity of mitral valve tenting associated with PPM displacement. Thus, surgeons routinely perform R-MA as a unique surgical solution for a complex LV disease. Several authors have proposed different surgical techniques (eg, PPM relocation, second chordae cutting, PPM sling) ${ }^{11-13}$ in addition to R-MA to improve long-term repair results. In this series, we present our experience on PPM relocation. This technique was first introduced by Kron and colleagues ${ }^{12}$ and may be easy and reproducible.

LV reverse remodeling has been observed after R-MA., ${ }^{4,8}$ However, it is not clear whether PPM relocation has a favorable effect on LV reverse remodeling for isolated R-MA. Our group recently published 2 articles that compare the results of PPM relocation and NR-MA with isolated R-MA. ${ }^{15,18}$ We demonstrated that PPM relocation reduces the tenting area and coaptation depth, leading to a low incidence of recurrent MR and promoting a better reverse in LV remodeling compared with isolated R-MA.

PPM relocation is a safe method, with low early and late mortality. This technique reduces the tenting area and coaptation depth, leading to a low incidence of recurrent MR and probably avoiding further displacement of the PPMs. Moreover, PPM relocation promotes a better reverse in LV remodeling.

\section{References}

1. Bonow RO, Carabello BA, Chatterjee K, de Leon AC, Faxon DP, Freed MD, et al. 2008 Focused update incorporated into the ACC/AHA 2006 guidelines for the management of patients with valvular heart disease. A report of the American College of Cardiology/American Heart Association Task Force on Practice Guidelines (Writing Committee to Revise the 1998 Guidelines for the Management of Patients With Valvular Heart Disease). Circulation. 2008;118: e523-661.
2. Vahanian A, Alfieri O, Andreotti F, Antunes MJ, Baròn-Esquivias G, Baumgartner $\mathrm{H}$, et al. Guidelines on the management of valvular heart disease (version 2012). The Joint Task Force on the Management of Valvular Heart Disease of the European Society of Cardiology (ESC) and the European Association for Cardio-Thoracic Surgery (EACTS). Eur Heart J. 2012;33:2451-96.

3. Bolling SF, Deeb GM, Brunsting LA, Bach DS. Early outcome of mitral valve reconstruction in patients with end-stage cardiomyopathy. J Thorac Cardiovasc Surg. 1995; 109:676-82.

4. Fattouch K, Guccione F, Sampognaro R, Panzarella G, Corrado E, Navarra E, et al. Efficacy of adding mitral valve restrictive annuloplasty to CABG in patients with moderate ischemic mitral valve regurgitation: a randomised trial. J Thorac Cardiovasc Surg. 2009;138:278-85.

5. Gillinov AM, Wierup PN, Blackstone EH, Bishay ES, Cosgrove DM, White J, et al. Is repair preferable to replacement for ischemic mitral regurgitation? J Thorac Cardiovasc Surg. 2001;122:1125-41.

6. Adams DH, Chen RH, Byrne JG, Filsoufi F, Cohn LH, Aklog L, et al. Improving outcomes in patients with moderate ischemic mitral regurgitation undergoing combined CABG and mitral annuloplasty. Circulation. 2000;102(Suppl II): II-462.

7. Vassileva CM, Boley T, Markwell S, Hazelrigg S. Meta-analysis of short-term and long-term survival following repair versus replacement for ischemic mitral regurgitation. Eur J Cardiothoracic Surg. 2011;39:295-303.

8. Bax JJ, Braun J, Somer ST, Klautz R, Holman ER, Versteegh MI, et al. Restrictive annuloplasty and coronary revascularization in ischemic mitral regurgitation results in reverse left ventricular remodeling. Circulation. 2004; 110(Suppl II):II-103-8.

9. Kuwahara E, Otsuji Y, Iguro Y, Ueno T, Zhu F, Mizukami N, et al. Mechanism of recurrent/persistent ischemic/functional mitral regurgitation in chronic phase after surgical annuloplasty: importance of augmented posterior leaflet tethering. Circulation. 2006;114:I-529-34.

10. Mihaljevic T, Lam BK, Rajeswaran J, Takagaki M, Lauer MS, Gillinov AM, et al. Impact of mitral valve annuloplasty combined with revascularization in patients with functional ischemic mitral regurgitation. J Am Coll Cardiol. 2007;49: 2191-201.

11. Messas E, Guerrero JL, Handschumacher MD, Conrad C, Chow CM, Sullivan S, et al. Chordal cutting: a new therapeutic approach for ischemic mitral regurgitation. Circulation. 2001;104:1958.

12. Kron IL, Green GR, Cope JT. Surgical relocation of the posterior papillary muscle in chronic ischemic mitral regurgitation. Ann Thorac Surg. 2002;74:600-1.

13. Hvass U, Tapia M, Baron F, Pouzet B, Shafy A. Papillary muscle sling: a new functional approach to mitral repair in patients with ischemic left ventricular dysfunction and functional mitral regurgitation. Ann Thorac Surg. 2003;75: 809-11.

14. Carpentier A. Cardiac valve surgery: the "French correction" J Thorac Cardiovasc Surg. 1983;86:323-37.

15. Fattouch K, Lancellotti P, Castrovinci S, Murana G, Sampognaro R, Corrado E, et al. Papillary muscle relocation in conjunction with valve annuloplasty improve repair results in severe ischemic mitral regurgitation. J Thorac Cardiovasc Surg. 2012;143:1352-5.

16. Braun J, Bax JJ, Versteegh MI, Voigt PG, Holman ER, Klautz RJ, et al. Preoperative left ventricular dimensions predict reverse remodeling following restrictive mitral annuloplasty in ischemic mitral regurgitation. Eur J Cardiothorac Surg. 2005;27:847-53.

17. Ciarka A, Braun J, Delgado V, Versteegh M, Boersma E, Klautz R, et al. Predictors of mitral regurgitation recurrence in patients with heart failure undergoing mitral valve annuloplasty. Am J Cardiol. 2010;106:395-401.

18. Fattouch K, Murana G, Castrovinci S, Nasso G, Speziale G. The role of papillary muscle relocation in ischemic mitral valve regurgitation. Semin Thorac Cardiovasc Surg. 2012;24:246-53. 